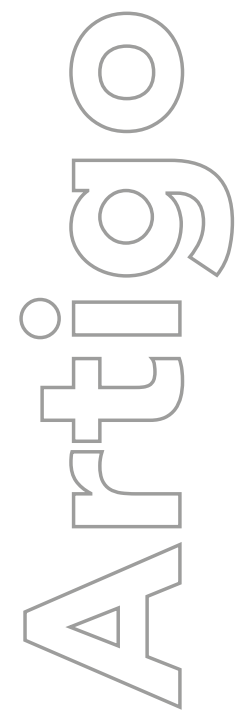

revista

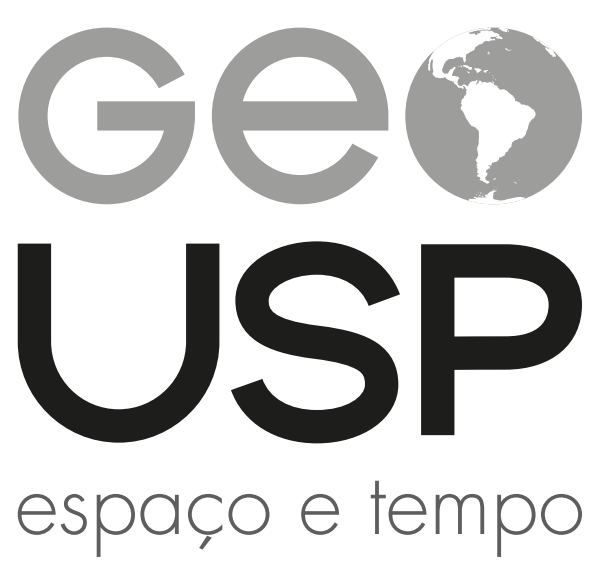

Volume $25 \cdot n^{\circ} 2$ (2021)

ISSN 2179-0892

\section{Parques temáticos e aquáticos no Brasil}

Alexandre Queiroz Pereira

Universidade Federal do Ceará. Fortaleza. Ceará. Brasil aqpufc@gmail.com

(1) 0000-0001-7560-6064

Eustogio Wanderley Correia Dantas

Universidade Federal do Ceará. Fortaleza. Ceará. Brasil ewcdantas@gmail.com

(1) 0000-0001-9656-1328

e-182522

Como citar este artigo:

PEREIRA, A. Q.; DANTAS, E. W. C. Parques temáticos e aquáticos no Brasil. Geousp, v. 25, n. 2, e-182522, 2021, ISSN 2179-0892.

Disponível em: https://www.revistas.usp.br/geousp/article/ view/182522. doi: https://doi.org/10.11606/issn.2179-0892. geousp.2021.182522.

\section{(c) $\underset{\mathrm{By}}{\mathrm{By}}$}

Este artigo está licenciado sob a Creative Commons Attribution 4.0 Licence 


\title{
Parques temáticos e aquáticos no Brasil $^{1}$
}

\section{Resumo}

Os parques temáticos e aquáticos são estruturas de lazer disseminadas por todos os continentes, configurando-se como importantes espaços turísticos. $\bigcirc$ Brasil também tem participação nesse sistema e apresenta exemplos caros à análise. Assim, objetivamos apreender a lógica espacial de instalação e funcionamento dos referidos no país convergindo como indutora e ao mesmo tempo induzida pelo processo de urbanização e metropolização do espaço, em tônica basilar de instituição do lazer como elemento central na reprodução das cidades e do urbano. Como base de dados, tomam-se os dados do relatório Global Attractions Attendance, da Themed Entertainment Association (TEA). A lógica de localização dos parques foi analisada por meio de cartografia multiescalar, mas sobretudo a regional e a metropolitana. A escolha analítica destaca a possível relação entre o urbano e o turístico ao refletir o papel desses parques na constituição de espacialidades semelhantes a complexos turísticos em zonas de expansão urbano-metropolitana.

Palavras-chave: Lazer. Espacialidade. Metrópole. Turistificação.

\section{Water parks in Brazil}

\begin{abstract}
Amusement and water parks are leisure structures spread over all continents, constituting important touristic spaces. Brazil also takes part in this system and presents important examples for analysis. Therefore, as premise, we understand the diffusion process of amusement and water parks as inducer-induced to broader processes, such as touristification, urbanization and metropolization of space. We think of a model of society where leisure conditions the reproduction of urban. As databases, they are used in the Themed Entertainment Association's Report, the Global Attractions Attendance. The parks' location logic, specially regarding
\end{abstract}

Os autores agradecem o financiamento da Capes PGPSE Processo n. 88887.123947/2016-00, do projeto Sistemas ambientais costeiros e ocupação econômica do Nordeste, da Capes PRINT Processo n. 88887.312019/2018-00, do projeto Integrated socio-environmental technologies and methods for territorial sustainability: alternatives for local communities in the context of climate change, do programa Capes/Funcap Processo n. 88887.165948/2018-00, do projeto Apoio às Estratégias de Cooperação Científica do Programa de Pós-Graduação em Geografia, e as bolsas de produtividade concedidas pelo CNPq. 
regional and metropolitan parks, was analyzed via multi-scale cartography. The analytical approach highlights the possible relation between urban and touristic by reflecting the role of these parks in the constitution of spaces similar to touristic complexes in urban-metropolitan expansion areas.

Keywords: Leisure. Spatiality. Metropolis. Touristification.

\section{Parques temáticos y acuáticos en Brasil}

\section{Resumen}

Los parques temáticos y acuáticos son estructuras de recreación diseminadas por todos los continentes, y son importantes espacios turísticos. Brasil también participa en este sistema y presenta ejemplos propios para el análisis. Siendo así, como premisa, el proceso de difusión de los parques temáticos y acuáticos se entiende como inductor-inducido de procesos más amplios, tales como la turistificación, la urbanización y la metropolización del espacio. Se piensa en un modelo de sociedad en el que la recreación es un condicionante de la reproducción de lo urbano. Como base de datos se utilizarán las informaciones del informe Global Attractions Attendance, de la Themed Entertainment Association (TEA). La lógica de ubicación de los parques fue analizada vía cartografía multiescalar, pero principalmente, la regional y la metropolitana. La elección analítica destaca la posible relación entre lo urbano y lo turístico al reflejar el papel de estos parques en la constitución de espacialidades semejantes a complejos turísticos en zonas de expansión urbano-metropolitana.

Palabras clave: Recreación. Espacialidad. Metrópolis. Turistificación.

\section{Introdução}

Em 1978, estreou nos EUA o programa televisivo A Ilha da Fantasia (Fantasy Island). A atração se passava em espaço insular, no Pacífico, com acesso, grosso modo, por via aérea. Não era uma ilha selvagem como a do náufrago Robson Crusoé. Na verdade, sua principal atração - e por que não dizer turística? - era a experiência fantasiosa baseada nos mais profundos desejos dos visitantes.

Hotéis, cenários e atrações marcam o estereótipo do empreendimento turístico concebido em função do lazer (Raluca; Gina, 2008; Milman, 2009). A Ilha da Fantasia é um exemplo ficcional do parque de diversões mais atraente, haja vista a flexibilidade das atrações, capazes de atender individualmente aos desejos dos visitantes. Um produto turístico sob medida. 
A ficção hollywoodiana revela outros casos a criar parques temáticos únicos. É o caso da franquia de filmes Jurassic Park/Jurassic World. Na sequência cinematográfica, a essência é recriar geneticamente seres pré-históricos e apresentá-los confinados numa ilha como atrações turísticas. Baseadas na imaginação reconstruída pelo cinema e pela televisão, as companhias disseminam imagens; os estúdios e demais companhias de entendimento tomam "os mundos" e seus respectivos personagens, antes restritos às telas, e ousam recriá-los em parques temáticos. O espetáculo, a aventura e os jogos são componentes históricos dos parques de diversão (Ryan; Shuo; Huan, 2010), contudo, os atuais caracterizam-se também por oferecer a segurança, o controle, a unidade e a comercialização de atrações globalizadas (Pan; Bahja; Cobanoglu, 2018; Brougère, 2000).

Exemplo mundialmente reconhecido é a Disneyland. Mesmo que o projeto inicial tenha sido pensado e implantado em Anaheim, Califórnia, EUA, no final dos anos 1950, é no estado da Flórida, no início dos 1970, no entorno da atual Região Metropolitana de Orlando (Sims; Mesev, 2011), que a empresa fundada por Walt Disney põe em prática seu plano de grande envergadura. Anualmente, parques temáticos, aquáticos e resorts atraem dezenas de milhões de visitantes. Passo dado pelo grupo Disney, e acompanhado por outras grandes companhias, como os Studios Universal, produziu espacialidade urbana associada ao lazer e ao turismo. Inequivocamente, esse modelo tem influenciado a criação de parques e de espacialidades semelhantes nos demais continentes (Brunel, 2017). É possível, inclusive, mencionar a formação de "indústria" global dos parques temáticos (Clavé, 2007).

$\bigcirc$ fortalecimento e a difusão dos parques temáticos criaram processo mais amplo, denominado dysnelandização (Brunel, 2017). Trata-se de homogeneização de formas, práticas e atrações a fundamentar a organização de espaços turísticos artificiais e naturais. Esse processo permite compreender as mudanças no imaginário e no olhar do turista contemporâneo (Urry, 2001). Os parques estão inscritos em movimento de massificação, associados ao desejo pelo simulacro, pelo "falso" tradicional, ou seja, "o autêntico reinventado melhor do que o original" (Brunel, 2017, p. 193) e, ao mesmo tempo, transformaram-se em negócio multimilionário (Deng, 2011).

Os parques temáticos são produtos históricos e filtram clara influência do urbanismo das cidades-jardim, da grandiosidade das exposições universais, dos jogos dos parques de diversão e, hoje, cada vez mais, dos cenários e personagens do cinema globalizado (Clavé, 1999; Bajac; Ottinger, 2010). Para Lukas (2008), os parques temáticos podem ser apreendidos pelas noções oasis, land, machine, show, brand e text. São oasis quando percebidos como refúgio em contraste com o caos do "mundo exterior". Por sua vez, a noção land revela o parque temático como composição de lugares e paisagens com a finalidade de gerar sensações. Ao destacar o componente machine, revela-se a incorporação de atrações mecanizadas e geradoras de movimento, desafio e aventuras. Os parques estão atrelados à noção show, haja vista o uso constante de exibições e performances músico-teatrais capazes de compor um enredo. Parques modernos constroem símbolos e marcas conhecidas e valiosas, daí a noção brand. Por fim, e em razão das demais, a noção text relaciona-se à metonímia que a expressão "parque temático" abraça, posto a agregar significado objetivo, naturalmente absorvido, ou seja, torna-se sinônimo para lugar capaz de reunir as noções apontadas.

De acordo com Duhamel (2017), tais complexos se denominam les comptoir touristique, espaços fechados com acesso regulado, a ocupar extensões importantes dos territórios e 
capazes de se correlacionar com outras formas turísticas e imobiliárias (resorts, condomínios e condoresorts). Ou seja, trata-se tanto do sazonal/turístico como do morar.

Como premissa, compreende-se o processo de difusão dos parques temáticos e aquáticos como indutor-induzido de processos mais amplos, a saber, a urbanização e a metropolização do espaço. Pensa-se num modelo de sociedade no qual o lazer é condicionante da reprodução do urbano (Zukin, 1995).

Apresentado o tema, o objetivo deste artigo é compreender a lógica espacial de instalação e funcionamento dos parques temáticos e aquáticos no Brasil. Para tanto, usam-se os dados do relatório Global Attractions Attendance, da Themed Entertainment Association (TEA). A escolha analítica destaca a possível relação entre o urbano e o turístico ao refletir o papel destes parques na constituição de espacialidades semelhantes a complexos turísticos em zonas de expansão urbano-metropolitanas. Ainda no que se refere à exposição dos argumentos e dos procedimentos explorados, destaca-se o diálogo com pesquisadores estrangeiros a fim de amadurecer as noções concernentes às funções urbanas e às turísticas associadas aos modelos de parques mencionados. A lógica de localização dos parques é analisada por meio de cartografia multiescalar, sobretudo a regional e a metropolitana.

\section{Parques, lazer e turismo}

Nos países do capitalismo central, o número de parques e de visitantes indica sua importância para o lazer e, sobretudo, para a economia dos lugares. EUA, Japão e Europa representam as principais bacias receptoras e emissoras. Contudo, a China, como em outras atividades, fortalece sua relevância no sudeste asiático. Semelhante aos dados de fluxo turístico internacional, - Brasil se mostra periférico tanto pelo número de parques temáticos como de seus visitantes.

$\bigcirc$ relatório Theme index and museum index (TEA; Aecom, 2017) exprime, inexoravelmente, a relevância da corporação Walt Disney Co. Dos dez parques mais visitados, oito levam a marca do Mickey Mouse (Quadro 1). A Ásia representa importante mercado e a Europa aparece a seguir. Ainda de acordo com o relatório, entre os 25 mais visitados, estão parques localizados na Coreia do Sul, Hong Kong, Singapura, França, Alemanha, Holanda e Dinamarca.

Segundo Clavé (1999), a façanha de Walt Disney foi transformar o parque em experiência turística, haja vista o alongamento da estada e, principalmente, o gasto médio por turista. Com os mesmos princípios de planejamento, em Orlando, na Flórida/EUA, os grupos Disney e Universal produziram um aglomerado de parques, uma megaespacialidade de lazer. Além desses dois, grupos internacionais como Merlin (britânico) e Parques Reunidos (espanhol) buscam novos mercados para construir ou comprar parques, inclusive em associação com grupos locais.

Como estratégia de expansão, Marc (2006) lembra a associação de grupos estadunidenses com outros grupos a fim de expandir as fronteiras, como a abertura do parque Disney no Japão nos anos 1980, e na França nos anos 1990 (Altman, 1999; Deville Chabrolle, 1999). Por outro lado, a concorrente Universal foi a primeira corporação a abrir negócios na China, mas podem ser lembrados os casos da Warner Bros. e da Viacom/Paramount Pictures. Por condições demográficas, abertura cultural e poder de compra, o continente asiático tornou-se espaço privilegiado, sobretudo Japão, Coreia do Sul e, destacadamente, a China. 


\section{Quadro 1 - Os dez parques mais visitados e a variação no número de visitantes entre 2016 e 2017}

\begin{tabular}{|c|l|c|c|c|}
\hline \multicolumn{2}{|l|}{ parque e localização } & $\begin{array}{l}\text { crescimento } \\
\text { (\%) }\end{array}$ & $\begin{array}{l}2017 \\
\text { (mil) }\end{array}$ & $\begin{array}{l}2016 \\
\text { (mil) }\end{array}$ \\
\hline 1 & Magic Kingdom at Walt Disney World, Lake Buena Vista, FL, US & 0,3 & 20.450 & 20.395 \\
\hline 2 & Disneyland, Anaheim, CA, US & 2,0 & 18.300 & 17.943 \\
\hline 3 & Tokyo Disneyland, Tokyo, Japan & 0,4 & 16.600 & 16.540 \\
\hline 4 & Universal Studios Japan, Osaka, Japan & 3,0 & 14.935 & 14.500 \\
\hline 5 & Tokyo Disneysea, Tokyo, Japan & 0,3 & 13.500 & 13.460 \\
\hline 6 & Disney's Animal Kingdom at Walt Disney World, Lake Buena Vista, FL, US & 15,3 & 12.500 & 10.844 \\
\hline 7 & Epcot at Walt Disney World, Lake Buena Vista, FL & 4,2 & 12.200 & 11.712 \\
\hline 8 & Hanghai Disneyland, Shanghai, China & 96,4 & 11.000 & 5.600 \\
\hline 9 & $\begin{array}{l}\text { Disney's Hollywood Studios at Walt Disney World, Lake Buena Vista, } \\
\text { FL, US }\end{array}$ & $-0,5$ & 10.722 & 10.776 \\
\hline 10 & Universal Studios at Universal Orlando, FL, US & 2,0 & 10.198 & 9.998 \\
\hline
\end{tabular}

fonte: TEA e Aecom (2017).

Os dados atualizados do Theme index and museum index (TEA; Aecom, 2018) demonstram os três grandes polos mundiais de parques. Os mais importantes são a costa leste americana, a Europa ocidental e o leste asiático. Nestes espaços, os parques temáticos chegam a 20 milhões de visitantes por ano. Já os parques aquáticos, comuns na zona tropical, receberam no máximo 2,7 milhões anuais (Figura 1).

\section{Figura 1 - Números de visitantes nos principais parques temáticos e} aquáticos -2018

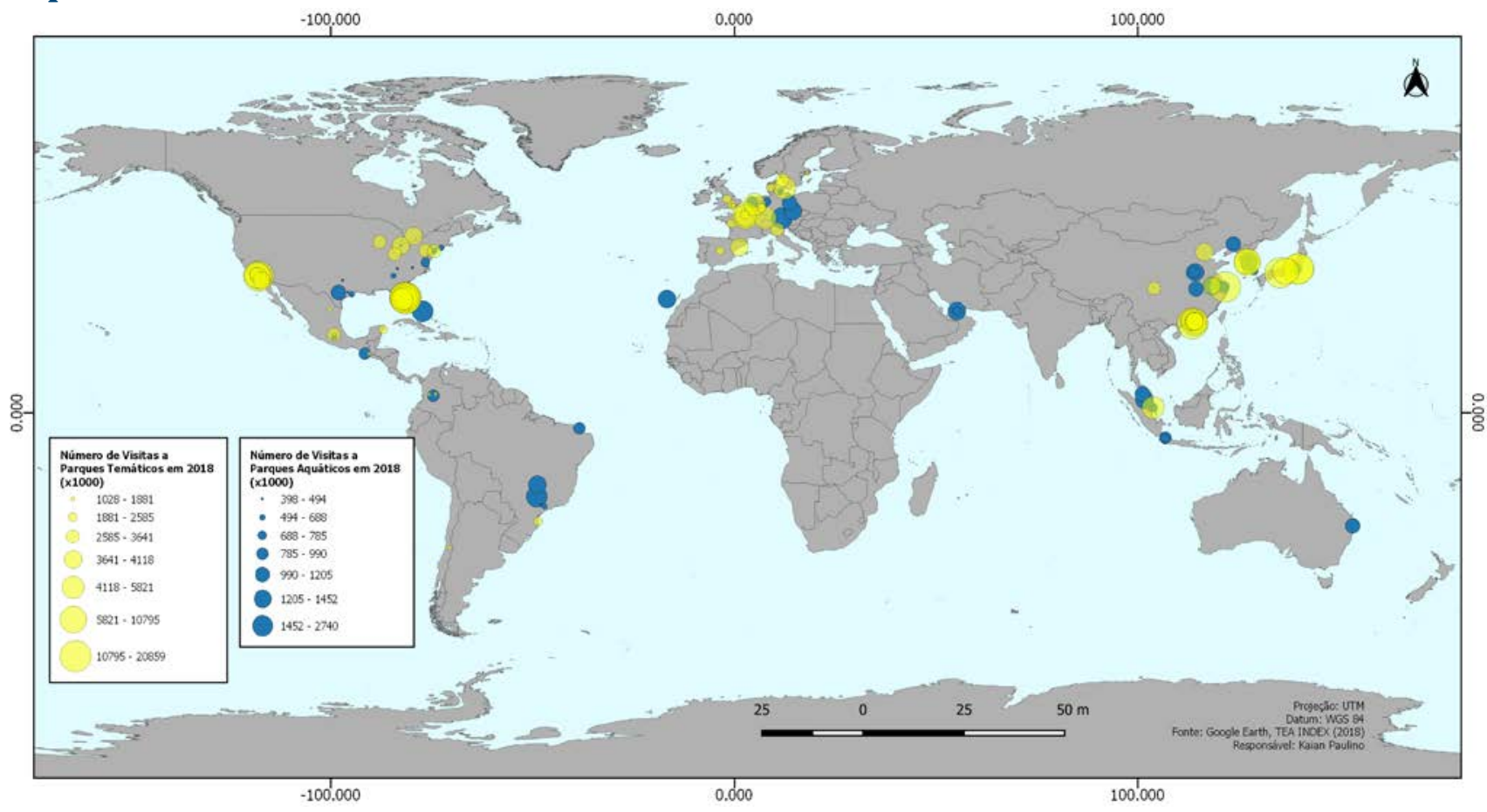

fonte: TEA e Aecom (2018). 
Para explicar essas localizações, Brunel (2017) relaciona o processo de mundialização ao de moyennisation, ou melhor dizendo, ao crescimento da classe média emprestando vigor ao mercado consumidor. De acordo com a autora, os parques fazem uma justaposição de universos reconstruídos para proporcionar a ilusão do real. Evidencia-se a potência do setor turístico, posto ser capaz de articular, num dado lugar, a ideia de sucessão de lugares (múltiplas escalas).

De acordo com Marc (2006), em média, um em cada dois europeus costuma visitar parques pelo menos uma vez ao ano. Os americanos, por sua vez, mais de uma vez ao ano. Em termos gerais, o perfil social dos visitantes é constituído por familias e adolescentes. Para o caso do parque espanhol Port Aventura, um quarto dos 3 milhões de visitantes é de estrangeiros e aproximadamente dois milhões (2/3) moram a duas horas e meia de distância do parque (Marc, 2006). $\mathrm{Na}$ França, os cinco maiores parques captam 80\% de apreciadores desse tipo de atração: Parc Walt Disney Studios (43 km de Paris), Disneyland Paris (42 km), Parque Astérix (46 km), Puy du Fou (382 km) e Futuroscope (322 km) (Brunel, 2017; Cazes, 1988).

A classificação dos parques depende, majoritariamente, das variáveis magnitude do investimento, dimensão do projeto, competência, preços, condições ambientais e qualidade da gestão (Clavé, 1999). A partir destas, é possível correlacionar sua localização e abrangência, se regionais (a atender população próxima - de até 2 horas de deslocamento de automóvel) ou de destino turístico (a receber fluxo turístico nacional e internacional). Ao expor resultados de pesquisas acerca dos parques aquáticos na Espanha, Marc (2006) lembra as particularidades do meio aquático como forte atrativo e apelo turístico, por exemplo, os espanhóis Port Aventura e Costa Caribe. Contudo, há algo em torno de 36 parques dessa natureza concentrados na costa sudeste do país (Marc, 2006).

Por sua vez, os parques aquáticos representam um segmento importante dos parques de diversão. As atrações baseadas em toboáguas e mergulhos rápidos, correntezas e praias artificiais demonstram a importância da água como elemento lúdico e de lazer. Para Marc (2006), os parques oferecem uma alternativa ao prazer derivado do mar e associam-se, a partir dos anos 1970, à invenção e/ou adaptação de várias práticas esportivas náuticas ou aquáticas. Ao mesmo tempo, a fim de evitar a perda de atratividade, há um movimento contínuo de inovação e modernização dos espaços internos ao parque com lançamento de "brinquedos", shows e promoções.

\section{Os parques no Brasil e suas dimensões urbana e regional}

A relevância econômica e turística dos parques é ratificada pelo número de parques e visitantes, pela distribuição mundial e, sobretudo, pelo poderio econômico das corporações de entretenimento envolvidas. Os parques não são simples lugares turísticos (Behar-Bannelier, 2008), e tampouco sua relação com o processo de crescimento das franjas urbano-metropolitanas e/ou impactos urbanos em bacias regionais.

A localização dos parques explica-se pela simultaneidade de condições. A primeira, a situação geográfica favorável, é capaz de possibilitar acesso a partir das aglomerações urbanas e, a segunda, de caráter indutor, é o processo de incorporação de áreas, reorganizadas em formas e funções urbanas. Baron-Yelles e Clavé (2014) mencionam que tais escolhas locacionais se relacionam dialeticamente pela separação e dependência (localização isolada - indução - crescimento 
da cidade - preço do solo - novos zoneamentos). É evidente que há exceções, haja vista o isolamento locacional explorado como potência atrativa por determinados modelos de parques temáticos (Brunel, 2017). Autores como Clavé (1999, p. 96) advogam pela primazia de análises a destacar o caráter urbanizador dos parques, posto que "semelhante à cidade, um parque é, fundamentalmente, um espaço de concentração de população, de realização de funções, de localização de equipamentos e de prestação de serviços, contudo, seu caráter urbano é fictício". A construção e o funcionamento desses empreendimentos de lazer têm uma série de consequências mundialmente registradas: (i) ampliam áreas comerciais, hotéis e zonas de entretenimentos, (ii) agregam-se e formam um complexo turístico mais amplo, (iii) influenciam o redesenho de práticas de planejamento do uso do solo, gestão dos fluxos energéticos, transporte, comunicação, gestão de águas e resíduos e conservação dos espaços e (iv) grupos proprietários são capazes de associar-se ao Estado e adquirir "poderes" de organização e gestão do espaço urbano, inclusive de espaços públicos (Clavé, 1999).

Em abordagem próxima à anterior, Marc (2006) destaca a localização periurbana desses espaços fechados de lazer, que demonstra, nos casos europeus, a tendência de parques médios a construir resorts e hospedagens no entorno.

Ao investigar os parques Disneylandia e Futuroscope na França, Baron-Yelles e Clavé (2014) defendem a hipótese de que o modo de pensar os parques influencia o modo de pensar a cidade, a urbanidade e o lazer. Para os autores, a ideia aplicada aos parques representa um microcosmo e um laboratório para ações (design, vocábulos, imagens, formas) aplicadas a outra escala, a da metrópole. Tais infraestruturas de lazer representariam a modernização da metrópole.

Essas transformações não acontecem por acaso, haja vista o alinhamento e o compromisso público para a existência dos parques como os estudados. Tanto para a Disneyland Paris como para o Futuroscope, Baron-Yelles e Clavé (2014) detectam forte transformação do entorno, nas cidades e nos bairros, diretamente relacionada aos parques. Verifica-se espacialização e grande número de serviços urbanos alimentados por infraestruturas de transporte. $\bigcirc$ modelo de crescimento suburbano é evidente (Baron-Yelles, 2006).

Mas, no Brasil, qual a importância e como estão distribuídos os parques temáticos e aquáticos? Em que aspectos há, de fato, relação entre a localização desses empreendimentos e o crescimento urbano e turístico? Para apontar possíveis respostas a essas questões, indica-se a metodologia analítica-sintética, alicerçada em exposição a partir de duas escalas, a regionalnacional e a das aglomerações urbanas.

\section{Brasil: parques e distribuição regional}

De acordo com registros do Ministério do Turismo, o Brasil contava com 50 parques temáticos em 2018, seis a menos que no ano anterior. A maior mudança se deu na região Nordeste, onde esse número caiu de 23 em 2017 para 11 em 2018. Movimento inverso ocorreu na região Sul, onde se acrescentaram sete parques entre 2017 e 2018, totalizando recentemente 22 (Figura 2). De modo geral, a diminuição representa o descredenciamento dos pequenos parques ou até mesmo o fechamento das empresas. Mas tanto em relação ao tamanho como à capacidade de modernização, os parques brasileiros são modestos frente aos americanos, europeus e asiáticos. 
mapeamento do número de parques por estado dá uma primeira aproximação dessa geografia no Brasil. Os estados com maior número de parques são Rio Grande do Sul, Santa Catarina e Pernambuco, respectivamente, dez, oito e cinco parques. Nas regiões Norte e Centro-Oeste, essa tipologia de empreendimentos de lazer concentra-se num estado, respectivamente Pará e Goiás.

Além desses dados, é necessário considerar as informações relativas ao tamanho e à relevância nacional e regional, sobretudo ao número de visitantes anuais. Assim, os parques temáticos brasileiros podem ser classificados de acordo com sua capacidade de interação espacial; em outros termos, em função da abrangência originária do fluxo de visitantes. Cerca de 80\% dos parques atendem ao lazer de populações de cidades próximas, em média, a duas horas de deslocamento por automóvel.

\section{Figura 2 - Parques de diversão no Brasil - 2017 e 2018}
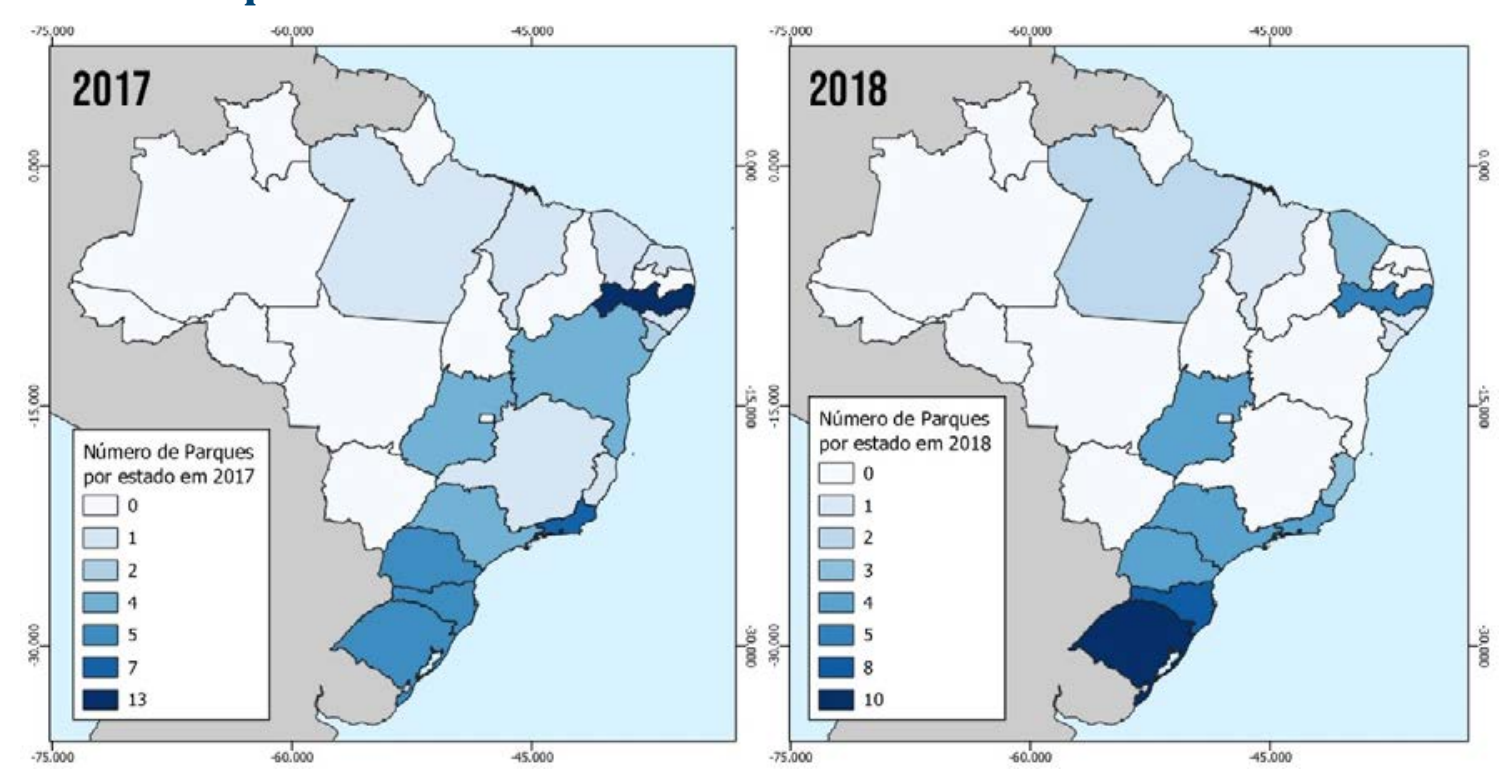

fonte: Brasil (2018).

Das dezenas de parques cadastrados no Ministério do Turismo, os dados do TEA e Aecom (2017) destacam nove de abrangência regional ou nacional a receber entre 243 mil e 2,2 milhões de visitantes/ano. Em 2018, o número cai para sete, em virtude do fechamento do parque Rio Water Planet (RJ) e de problemas técnicos/financeiros do Hopi Hari (SP).

Conforme a Figura 3, quatro são os principais polos a sediar os parques temáticos e/ou aquáticos no Brasil: (i) Penha, em Santa Catarina, sede do parque Beto Carrero World (2,1 milhões de visitantes/ano), (ii) Olímpia, no noroeste paulista, base dos parques Thermas dos Laranjais (1,9 milhões de visitantes/ano) e Hot Beach Olímpia (462 mil visitantes/ ano), (iii) Aquiraz, no Ceará, Região Metropolitana de Fortaleza, onde se localiza o Beach Park (950 mil visitantes/ano), e, por fim, (iv) Rio Quente, em Goiás, sede do Hot Park Rio Quente (1,4 milhões de visitantes/ano). 

2017 e 2018
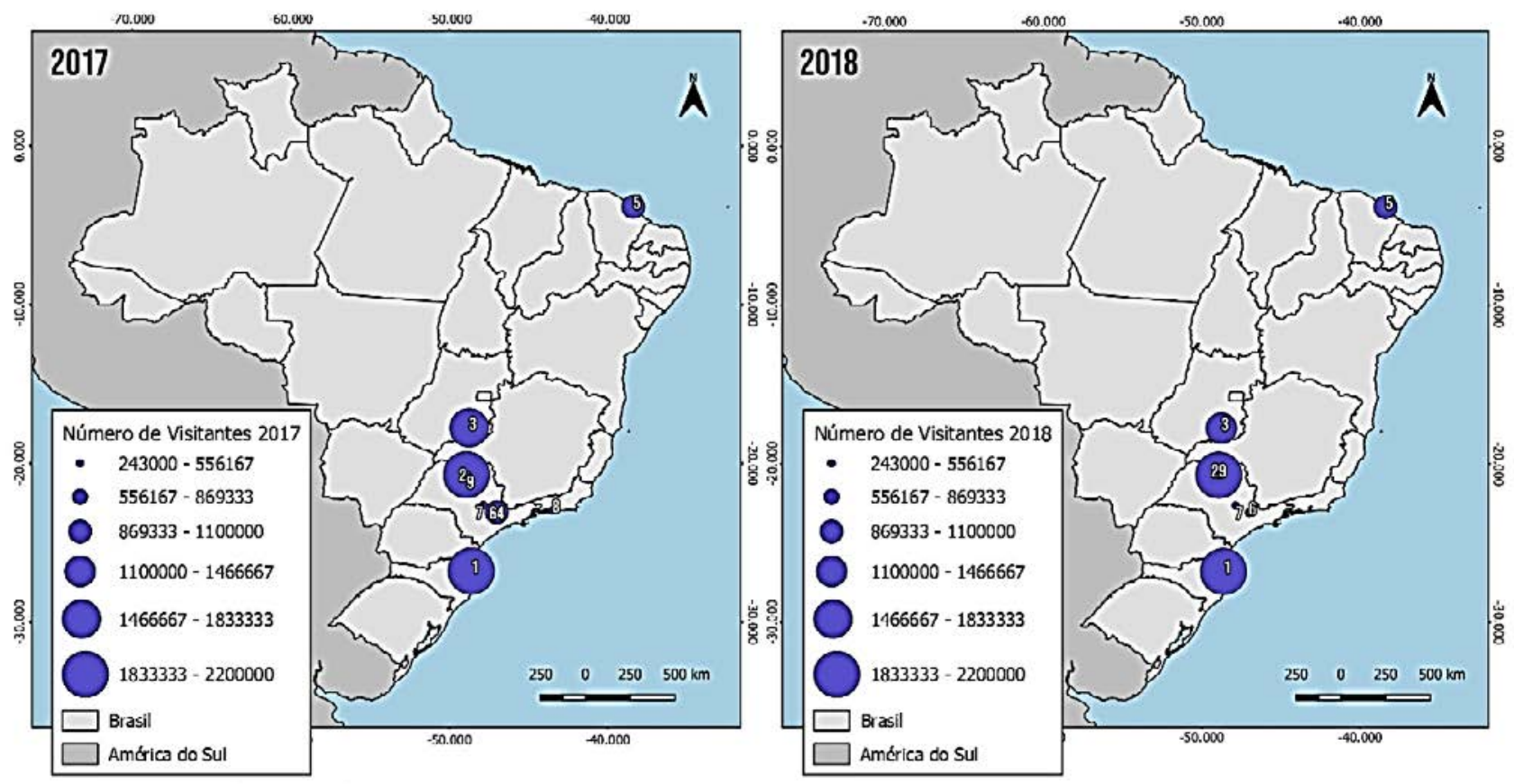

\section{LISTA DE PARQUES TEMÁTICOS E AQUÁTICOS BRASILEIROS 2017/2018}

1- Beto Carrero - 2.200.000/2.122.000 6-Wa'n Wild São paulo - $476.000 / 500.000$

2- Thermas dos Laranjais - 2.007.000 / 1.971.000 7- Thermas Water Park - $392.000 / 481.000$

3- Hot Park Rio Quente - 1.481.000/1.433.000 8 - Rio Water Planet - 372.000/ $0^{* *}$

4- Hopi Hari-1.028.000/ $0^{*}$

5 - Beach Park - $1.028 .000 / 950.000$

9 - Hot Bcach Olimpia - $243000 / 462000$

- No uno de 2018 o Parque Hopi Hari năo cntra para a

lista dos parques mais visitados da américa latina, pcrtanto os dados nảo sảo exibidos na pesquisa do Tea Index 2018. suas atividades.

fonte: TEA e Aecom (2018).

Entre os polos mencionados, pode-se estabelecer uma subdivisão baseada na origem do fluxo de turistas e derivar duas categorias. A primeira inclui os parques com forte dependência de um estado ou de uma região próxima. Nessa categoria, estão os parques em Olímpia e em Rio Quente. Dados do Convention E Visitor Bereau indicam que, em 2014, em Olímpia, cerca de $82 \%$ dos visitantes residiam no próprio estado, já em Rio Quente, 63\% dos visitantes eram paulistas e 13,5\%, do Distrito Federal (Carvalho, 2015). A proximidade e o fácil acesso às grandes bacias urbanas, localizadas em importantes centros econômicos do país, concorrem para entender esse quadro. A segunda categoria é a dos parques com atratividade turística nacional, na qual estão classificados o Beto Carrero World e o Beach Park. Estes são importantes âncoras turísticas dos seus respectivos estados, estão no roteiro de pacotes das operadoras nacionais de turismo e, por consequência, recebem turistas de todas as regiões do país e, em menor número, do estrangeiro (Santos, 1997; Rodrigues, 2016).

No que tange ao tema, o elemento água é o componente fundamental das atrações. Tanto o Thermas como o Hot Park, situados em regiões continentais, constituíram-se a partir de antigas estações de águas termais. $\bigcirc$ Beach Park, por sua vez, é integralmente baseado em elementos aquáticos e, sobretudo, fica à beira-mar, inclusive com estrutura de serviços na zona de praia. $\bigcirc$ parque Beto Carrero World é o mais diverso, com diferentes estímulos à diversão (brinquedos mecânicos, zoológico, shows temáticos), incluindo atrações baseadas no meio aquático (Figura 4). 
Figura 4 - Mosaico de imagens e representações das atrações dos parques

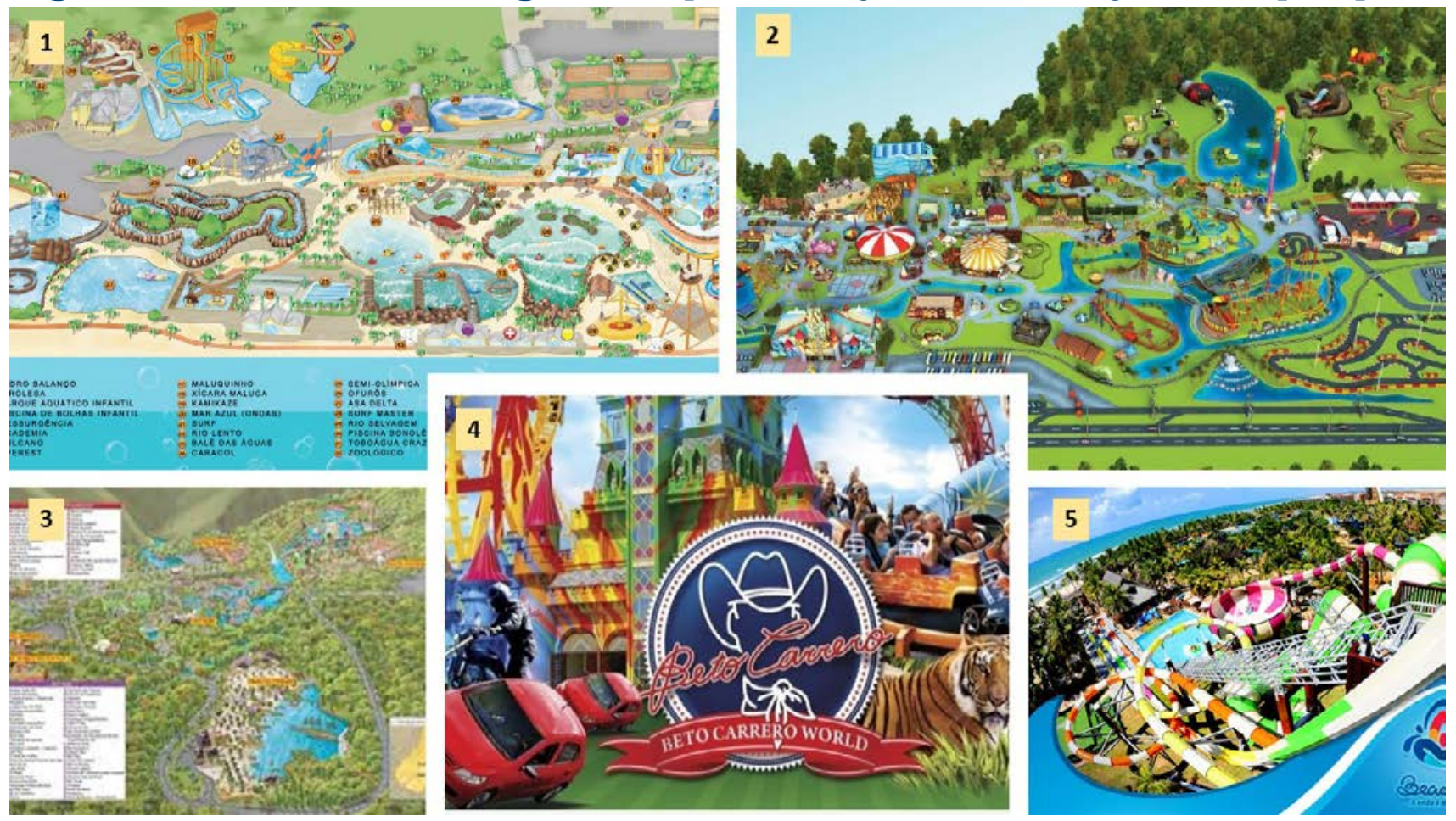

legenda: (1) Representação gráfica do parque Thermas dos Laranjais. (2) Figuração das atrações do Beto Carrero World. (3) Visão geral do parque Hot Park Rio Quente. (4) Marca reconhecida do Beto Carrero World e suas atrações. (5) Visão dos toboáguas e da zona de praia do Beach Park.

fontes: (1) https://www.acquathermas.com.br. (2) e (4) https://www.betocarrero.com.br. (3) https://www.rioquente.com. (5) https://www.beachpark.com.br

Indiretamente, o Beto Carrero World vincula-se à maritimidade, dada sua instalação no balneário marítimo de Armação, a um quilômetro da zona de praia. Assim como no Beach Park, os pacotes turísticos geralmente associam roteiros que incluem estada nas principais praias (Florianópolis e Balneário Camboriú) e pelo menos um dia de visitação ao parque.

\section{Os parques, o urbano e o metropolitano}

Em casos como a mancha urbana de Orlando, ou mesmo cidades da Île-de-France, os parques temáticos induziram transformações urbanas e regionais de grande magnitude. Para o caso americano, Clavé (1999) descreve o impacto da companhia Disney na organização espacial de mais de 1.100 hectares. A empresa de entretenimento recebeu condições diferenciadas de gerir o espaço urbano conforme suas necessidades, inclusive possibilidade de controle do zoneamento do uso do solo e regulação administrativa. Vislumbra-se modelo de planejamento e gestão urbanos baseado nas estratégias empresariais.

No Brasil, não são percebidas transformações da mesma grandeza e direcionamento; porém, é verificável a relevância urbana dos parques para as municipalidades onde eles estão localizados.

O perfil populacional dos municípios varia entre o pequeno Rio Quente, com população estimada em 4,4 mil habitantes e o município metropolitano de Aquiraz, com 80 mil. As condições socioeconômicas sintetizadas pelos indicadores salário médio, produto interno bruto (PIB) per capita e índice de desenvolvimento humano (IDH) municipal apontam condições semelhantes nos municípios do Centro-Sul e superiores aos dados constados no município cearense (Tabela 1). 


Tabela 1 - Dados socioeconômicos dos municípios sedes dos
parques temáticos
\begin{tabular}{|l|c|c|c|c|}
\hline $\begin{array}{l}\text { município de } \\
\text { localização dos } \\
\text { parques }\end{array}$ & $\begin{array}{l}\text { população } \\
\text { estimada } 2019\end{array}$ & $\begin{array}{l}\text { salário médio (em } \\
\text { salários-mínimos) }\end{array}$ & $\begin{array}{l}\text { PIB per capita } \\
\text { em } \mathbf{2 0 1 7} \text { (mil) }\end{array}$ & $\begin{array}{l}\text { IDH } \\
\text { municipal } \\
\mathbf{2 0 1 0}\end{array}$ \\
\hline Penha & 32.531 & 2,2 & 21,7 & 0,743 \\
\hline Rio Quente & 4.493 & 2,2 & 74,6 & 0,731 \\
\hline Olímpia & 54.772 & 2,8 & 38,3 & 0,773 \\
\hline Aquiraz & 80.271 & 1,9 & 27,8 & 0,641 \\
\hline
\end{tabular}

fonte: IBGE (2020).

fluxo anual de visitantes atraídos pelos parques frente ao número de habitantes dos municípios é um interessante indicador do impacto socioespacial. $\bigcirc$ Beach Park recebe anualmente 12,8 vezes a população de Aquiraz; Thermas dos Laranjais, 36,5 vezes a população de Olímpia; Beto Carrero World, 67 vezes a de Penha e o Hot Park, 318 vezes a população de Rio Quente. Esses fluxos remetem à necessidade de transformações, sobretudo face à construção de empreendimentos turísticos e imobiliários nas áreas do entorno dos parques.

A cidade de Olímpia contava, em 2010, com 3 mil leitos de hospedagem e, em 2018, o número foi elevado para 22,7 mil leitos. Essas mudanças são explicadas frente à construção de 6 resorts, 22 hotéis, 55 pousadas, 2 hotéis-fazenda e 2 hostels, e, igualmente, constatam-se formas modernas de aquisição do direito a usar imóveis, como o modelo multipropriedade (Toledo, 2020).

A outra estação de águas termais, Rio Quente, é o destino turístico com maior nível de organização no referente às demandas turísticas nacionais e internacionais. Além disso, apresenta 45,46\% dos seus domicilios na categoria de uso ocasional, a maioria, em flats, hotéis-residências, condhotéis e na forma de segunda residência tradicional (Carvalho, 2015).

No caso dos parques Beto Carrero World (BCW) e Beach Park (BP), há sensíveis diferenças na organização espacial de seus respectivos entornos. Por um lado, percebem-se impactos construtivos a seguir padrão de estação balnear, ou seja, aglomeração de residências secundárias, empreendimentos imobiliários-turísticos, além de outros meios de hospedagem. Por outro lado, a relevância dos fluxos turísticos atraídos pelos parques dilui-se ou reverbera em contextos urbano e regional mais amplos.

O município de Penha, e mais especificamente, a Praia de Armação, sediam BCW e apresentam rebatimentos econômicos e turísticos a ponto de a cidade ser intitulada como cidade do turismo de parque temático. Entretanto, além da área ocupada pelo parque (mais de 1,5 milhões de $\mathrm{m}^{2}$ ), são constatados meios de hospedagens modestos, como pousadas e pequenos hotéis. Há diferença significativa quanto à concentração de padrões imobiliários e turísticos encontrados em Olímpia e Rio Quente.

Imagina-se que os efeitos, nesse caso, estão espalhados em outros balneários e cidades, basta averiguar a proximidade do parque com as cidades de Florianópolis (110 km), Curitiba (198 km), Balneário Camboriú (35 km) e Itajaí (23 km). Além das distâncias, as infraestruturas de acesso facilitam os deslocamentos aéreos (aeroporto de Florianópolis e de Navegantes) e, por terra, pela rodovia costeira BR-101 (Figura 5). Ao mesmo tempo, vale lembrar 
a distribuição dos efeitos turísticos em circuito de balneários litorâneos, denominado Rota do Sol e incluindo as praias de Balneário Camboriú, Itapema, Bombinhas, Porto Belo, Itajaí e Balneário Piçarras. Assim, é compreensível o modelo baseado em hospedagem (estada) em qualquer uma dessas praias e deslocamento diário (sem pernoite) para visitação do parque.

\section{Figura 5 - Localização geográfica do Beto Carrero World}

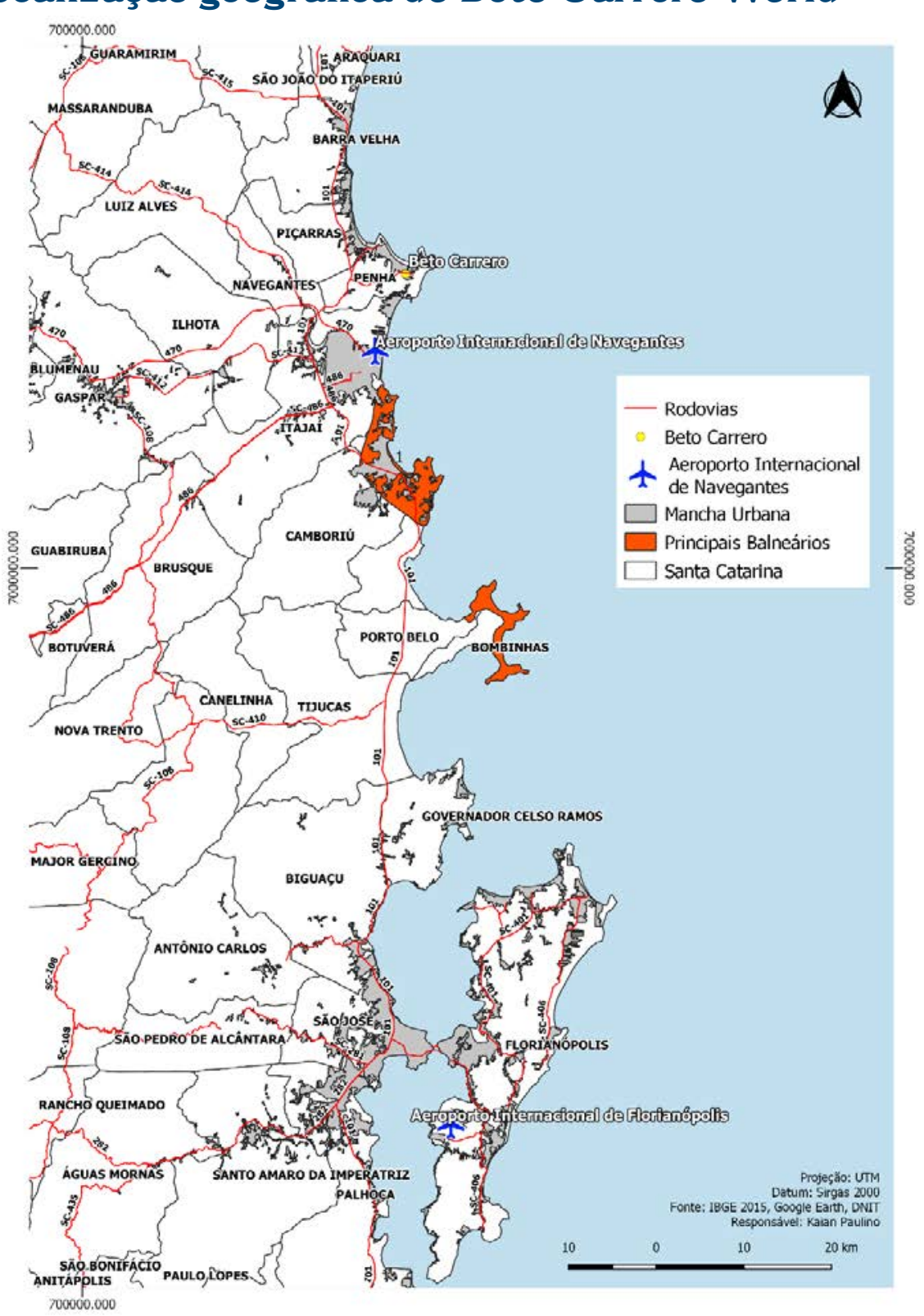

fonte: IBGE (2020) e trabalho de campo.

A situação geográfica do BP e os efeitos na organização espacial do seu sítio urbano são hibridos frente aos dos outros casos descritos. A primeira diferença é sua inserção na tessitura de uma metrópole de mais de 3 milhões de habitantes, assim como a proximidade com a cidade de Fortaleza (23 km do aeroporto internacional e da principal zona hoteleira) (Figura 6). Essa localização permite que, pela rodovia CE-025, parte dos visitantes do BP visitem Aquiraz unicamente para usar o parque e se hospedem na capital do estado ou em outros balneários na metrópole, possibilidade que mostra os fluxos capazes de interconectar os espaços intrametropolitanos de lazer. 
Figura 6 - Localização geográfica do Beach Park

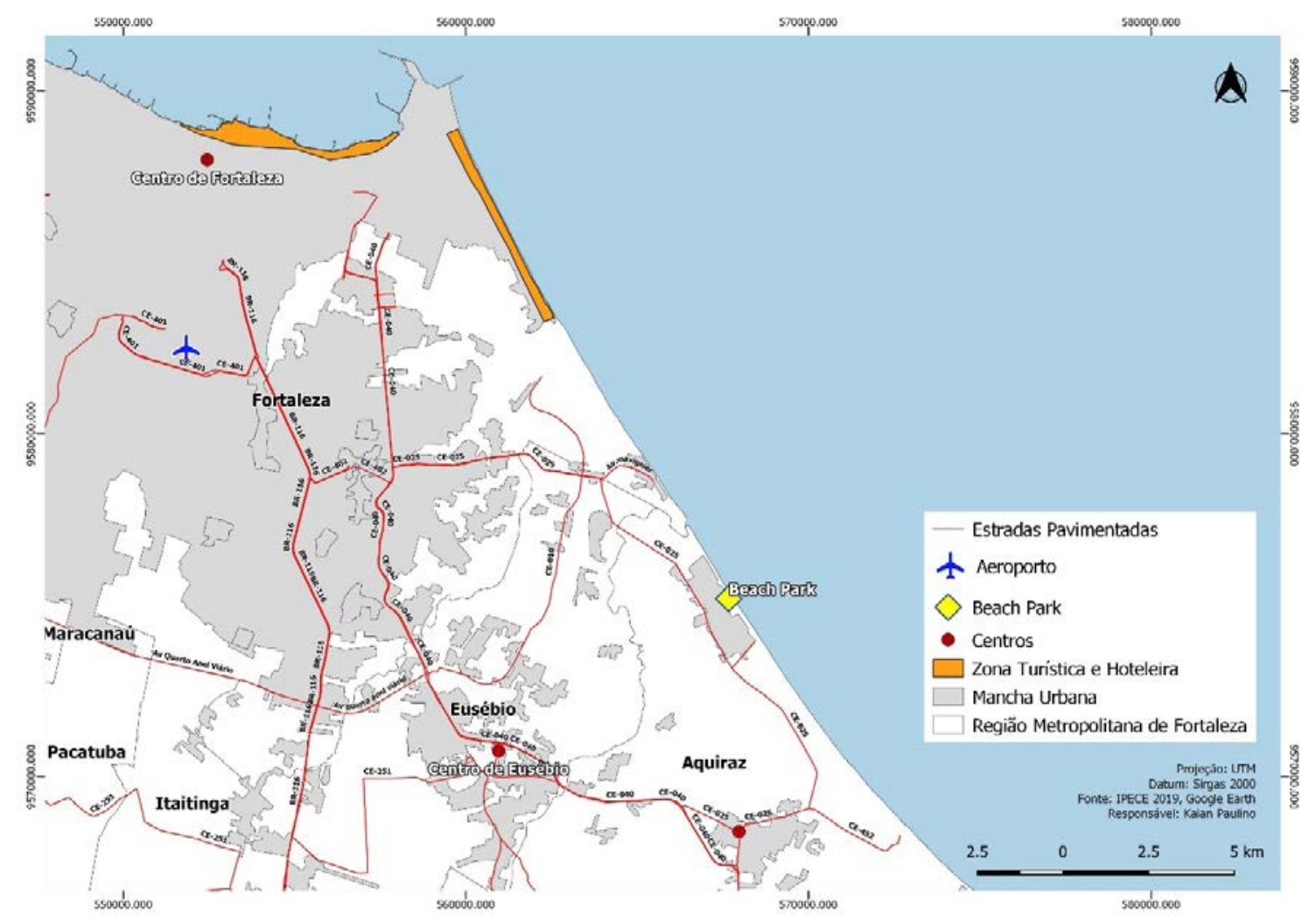

fonte: IBGE (2020) e trabalho de campo.

O BP deriva de um restaurante a beira mar, situado ocupando megalote em parcelamento de terra constituído nos anos 1980; a diversificação das atrações e o reconhecimento nacional deu-se a partir dos anos 1990. Inicialmente, cercado por residências secundárias individuais (unifamiliares), nos anos 2000, os grandes lotes a beira mar foram ocupados por residências verticais e resorts. $\bigcirc$ próprio grupo empresarial que administra o BP incrementou a estratégia e, além do entretenimento, incluiu-se na produção imobiliária e hoteleira com a construção de empreendimentos total ou parcialmente integrados ao parque (Acqua Beach Park Resort, Suites Beach Park Resort, Wellness Beach Park Resort e o Beach Park Oceani Resort) (Paiva; Diogenes, 2017).

Em entrevista registrada no site da Associação para o Desenvolvimento do ImobiliárioTurístico (ADITBrasil), Murilo Pascoal, CEO do BP, registra as transformações no plano de negócio do parque, destacando o crescimento em número de funcionários, visitantes e a abertura à hotelaria e ao imobiliário. Ao lembrar da importância do Vacance Club para a empresa, o gestor destaca o objetivo de expandir o número de apartamentos disponíveis, chegando a 1.000 unidades. Ao mesmo tempo, a entrevista demarca a importância da propriedade fundiária nos espaços litorâneos, visto a inexistência de lotes vazios contínuos ao parque. $\bigcirc$ entrevistado menciona os planos de construção de um novo parque, menor do que o atual, também localizado em Porto das Dunas e com capacidade para 2.000 pessoas/dia (Cavalcante, 2020).

A partir da primeira década do século XXI, no balneário de Porto das Dunas, sob forte influência da imagem turística do BP, verificam-se os empreendimentos Aquaville, Parque das Ilhas, Condomínio PortaMaris Resort, Vila do Porto Resort, Paraíso das Dunas, Oceani Beach Park, Atlantic Palace Apart-Hotel, Scopa Beach Resort, Beach Living, Beverly Hills, 
Condomínio Mediterranee, Condomínio Porta Firenze, Beach Way Residence, Condomínio TerraMaris, Condomínio Gransol, Condomínio Costa Blanca e, os mais atuais, GolfVille Resort e os Mandaras Lanai e Kauai. Inequivocamente, o gosto pelo mar e pelo marítimo associado às sinergias positivas derivadas da constante atualização do parque propiciaram significativa dinâmica do mercado imobiliário e turístico (Pereira; Gomes, 2018; Pereira; Cunha, 2019).

$\bigcirc$ parque e os empreendimentos turísticos e imobiliários são a base da produção do espaço nesse trecho do litoral. As empresas, por seleção espacial, repetem a prática da coesão, da interconectividade e das sinergias entre os empreendimentos de lazer. Contudo, diferentemente de grandes operações urbanas dos parques em Orlando ou nos arredores de Paris, sobretudo no caso de Porto das Dunas, a transformação da área se dá pelo acréscimo de construções, mas sem redefinições urbanísticas a melhorar os espaços públicos (ruas, calçadas, passeios, praças, acesso à praia etc.). Os marcos básicos da ocupação se dão pelo loteamento dos anos 1980, e os serviços são de responsabilidade da administração municipal, inclusive por sérias reclamações pela falta de pavimentação, drenagem de ruas e mobiliário urbano.

Além das infraestruturas, outra marca da relação entre os parques e o Estado é a questão fiscal. Nesse sentido, tanto para ampliação como para funcionamento, há negociação constante a fim de convencer as administrações públicas em conceder isenções ou redução de alíquotas de impostos. $\bigcirc \mathrm{BP}$, por exemplo, para as futuras instalações, anunciou acordo com o estado do Ceará e com o município de Aquiraz e garantiu isenção de 100\% no Imposto de Circulação de Mercadorias e Serviços (ICMS), além de outros benefícios associados a impostos municipais (Imposto Sobre a Transmissão de Bens e Impostos - ITBI, Imposto Sobre Serviços - ISS e Imposto Predial e Territorial Urbano - IPTU). A empresa J. B. World Entretenimentos, proprietária do BCW, pleiteia junto à prefeitura de Penha passagem da alíquota do ISS de 5\% para $2 \%$, redução que renderia economia anual milionária. Além das isenções fiscais, empréstimos a menor custo também marcam a relação desse tipo de empreendimento com o Estado brasileiro. Para sua ampliação, o parque localizado em Santa Catarina investiu em 2019 cerca de R \$ 89 milhões, dos quais $\mathrm{R} \$ 50,4$ milhões foram emprestados pelo Banco Nacional do Desenvolvimento (BNDES investe..., 2019).

Sem dúvidas, os parques, no Brasil, transformam os lugares a partir das instalações e da atração de empreendimentos voltados ao lazer, turismo e dinâmicas imobiliárias. Além disso, ao considerar a expressão urbana populacional dos municípios onde se localizam, é possível verificar a promoção de urbanização dos territórios. Não obstante, representam, primeiro, players econômicos decisivos para as municipalidades em razão dos serviços; e segundo, seus dirigentes tornam-se agentes produtores do território, face ao crescimento do mercado hoteleiro e do imobiliário que induzem.

\section{Considerações finais}

Os parques temáticos chegam ao século XXI na condição de importantes indutores do fluxo turístico mundial. Ganham espaço tanto em destinos consolidados (Paris, Orlando) como em novos (Singapura, Seul, Xangai). Para isso, as grandes companhias de entretenimento têm papel destacado, principalmente a Walt Disney. Essas são eficazes na divulgação, modernização 
e criação de padrões replicados em parques mundo afora. Inclusive, atualmente, as companhias promovem uma relação indissociável entre cinema, programas televisivos e a reinvenção desses espaços turísticos.

$\bigcirc$ Brasil se encontra na periferia desse circuito, com números acanhados diante dos europeus, norte-americanos ou do leste asiático. Assim como é característica do fluxo turístico brasileiro, os quatro principais parques têm a maior parte de seus visitantes no turismo doméstico. No que tange à dimensão temática, a espacialização dos parques, no Brasil, se explica claramente pela relação com a água. Os principais parques ficam em três estados situados na região Centro-Sul, sendo o Beto Carrero World o mais complexo e próximo aos modelos internacionais de parques temáticos. A exceção locacional é o Beach Park, no Nordeste, intrinsecamente associado à maritimidade moderna.

Na escala das transformações urbanas induzidas, percebe-se o nível de centralidade constituído com a instalação e o desenvolvimento dos parques. No caso dos localizados em Olímpia e Rio Quente, há redefinição do espaço construído com especialização funcional e associação entre os parques, hotelaria e imóveis destinados a uso sazonal. Os núcleos urbanos tornam-se intrinsecamente dependentes dessas estruturas de lazer, mais fortemente no caso de Rio Quente. Em Penha, a Praia de Armação sedia o Beto Carrero World e integra uma rede de balneários litorâneos, entre eles, as praias de Florianópolis e as de Balneário Camboriú. $\bigcirc$ parque é um importante elemento de uma rede de espaços turísticos, a principal da região Sul do Brasil, composta ainda por densa malha viária e dois aeroportos.

Dos grandes parques no Brasil, o Beach Park é o único situado na tessitura metropolitana. Integra e promove centralidade na metrópole com função turística e de lazer fortemente constituída. A partir dos anos 2010, a associação entre as atividades do parque, de hotelaria e dos interesses da incorporação imobiliária pauta a produção do espaço urbano. $\bigcirc$ eixo rodoviário da CE-025, além de acesso e ligação da sede metropolitana ao parque, torna-se zona demandada por atividades terciárias e outros produtos imobiliários, com certo adensamento de formas urbanas. Pensa-se que há relação direta entre a espacialidade do lazer em Porto das Dunas e as mudanças metropolitanas apontadas.

Por fim, tanto em função de mudanças no ordenamento fiscal como por investimentos em infraestrutura de acesso, os recursos públicos são usados para tais mudanças no espaço turístico. Os dirigentes dos parques e demais empresas de lazer fazem tratativas constantes com os diferentes gestores públicos executivos a fim de ampliar isenções fiscais (Beto Carrero World) e construir infraestruturas urbanas inexistentes (Beach Park).

Institui-se lógica de ordenamento do espaço associada a um modelo de sociedade no qual o lazer tem um papel preponderante na constituição da cidade e do urbano, reforçando o processo de urbanização e metropolização associado a interesses de empreendedores turísticos e imobiliários na escala do país. Um gênero de abordagem fundante e a ser complementada, em estudos futuros, com análise dos impactos sociais (expulsão lenta e gradual das comunidades tradicionais de seu territórios) e ambientais (degradação dos geossistemas). 


\section{Referências}

ALTMAN, Y. A theme park in a cultural straitjacket: the case of Disneyland Paris France. Managing Leisure, v. 1, n. 1, p. 43-56, 1999. doi: https://doi.org/10.1080/136067195376565.

ARCHER, K. The limits to the Imagineered City: sociospatial polarization in Orlando. Economic Geography, v. 73, n. 3, p. 322-336, 1997. doi: https://doi.org/10.2307/144487.

BAJAC, Q.; OTTINGER, D. (ed.). Dreamlands: des parcs d'attractions aux cités du futur. Paris: Centre Pompidou, 2010.

BARON-YELLES, N. La place de l'urbain dans les relations entre la nature et le tourisme: réflexions prospectives. POUR - Revue du Groupe de Recherche pour l'Education et la Prospective, n. 191, p. 35-42, 2006.

BARON-YELLES, N.; CLAVÉ, S. A. Leisure parks: components and creators of the new urban landscapes? Society and Leisure, v. 37, n. 1, p. 18-37, 2014. doi: https://doi. org/10.1080/07053436.2014.881090.

BEHAR-BANNELIER, L. Les paysages thématisés de Disneyland Resort Paris. Espaces, n. 2, p. 24-32, 2008.

BNDES INVESTE R $\$ 50$ milhões no Beto Carrero World. 2019. Disponível em: https://www. bndes.gov.br/wps/portal/site/home/imprensa/noticias/conteudo/bndes-investe-r50-milhoesno-beto-carrero-world. Acesso: 21 maio 2021.

BRASIL. MINISTÉRIO DO TURISMO. Anuário Estatístico de Turismo 2018. Dados e fatos. Disponível em: http://www.dadosefatos.turismo.gov.br/. Acesso em: 24 maio 2021.

BROUGÈRE, G. Les parcs d'attractions : jeu, divertissement, éducation. Educação e pesquisa. São Paulo, v. 26, n 1, p. 11-21, jan/jun, 2000. doi: https://doi.org/10.1590/ S1517-97022000000100002..

BRUNEL, S. Tourisme et "disneylandisation". In: FAGNONI, E. (dir.). Les espaces du tourisme et des loisirs. Paris: Armand Colin, 2017. p. 192-204.

CARVALHO, G. L. A. Política de turismo no estado de Goiás: um estudo sobre as escalas institucionais de intervenção. Tese (Doutorado em Geografia) - Centro de Ciências, Universidade Federal do Ceará, Fortaleza, 2015.

CAVALCANTE, F. Murilo Pascoal, CEO do Beach Park, conversa sobre a trajetória desse ícone e analisa o setor de parques aquáticos no Brasil. Maxt Podcast. 16 jan. 2020. Disponível em: https://anchor.fm/matx-podcast/episodes/Murilo-Pascoal--CEO-doBeach-Park--conversa-sobre-a-trajetria-desse-cone-e-analisa-o-setor-de-parquesaquticos-no-Brasil-ea6qq0. Acesso em: 21 maio 2021.

CAZES, G. Les grands parcs de loisir en France: réflexions sur un nouveau champ de recherches. Travaux de 1'Institut Géographique de Reims, n. 73-73, p. 39-56, 1988. doi: https://doi.org/10.3406/tigr.1988.1224.

CLAVÉ, S. A. The global theme park industry. Oxfordshire, GB: CABI Head Office, 2007. 
CLAVÉ, S. A. El desarrollo de parques temáticos en un contexto de globalización. Boletín de la AGE, n. 28, p. 85-102, 1999.

DENG, $X$. The development of theme parks in China. Thesis - Southern Illinois University, Carbondale, IL, 2011.

DEVILLE CHABROLLE, $V$. Parcs d'attractions: manèges et management à l'américaine. Santé \& Travail, n. 45, p. 23-44, 1999.

DUHAMEL, P. Géographie du tourisme et des loisirs: dynamiques, acteurs, territoires. Paris: Armand Colin, 2017.

LUKAS, S. A. Themes Park. London: Reaktion, 2008.

MARC, I. L'essor des parcs aquatiques en Espagne. In: SALAÜN, S.; ÉTIENVRE, F. Ocio y ocios: du loisir aux loisirs (Espagne XVIIle-XXe siècles). Paris: Université Sorbonne Nouvelle, 2006. Disponível em: https://crec-paris3.fr/wp-content/uploads/2011/07/ 04-marc.pdf. Acesso em: 21 maio 2020.

MILMAN, A. Evaluating the guest experience at theme parks: an empirical investigation of key attributes. International Journal of Tourism Research, v. 11. n. 4, p. 373-387, 2009. doi: https://doi.org/10.1002/jtr.710.

PAIVA, R. A.; DIOGENES, B. H. N. "Learning from Beach Park": o lugar do complexo turístico-imobiliário no processo de urbanização turística da Região Metropolitana de Fortaleza (Ceará). In: XVII ENANPUR - Encontro Nacional da Associação Nacional de Pós Graduação e Pesquisa em Planejamento Urbano e Regional, 17., 2017, São Paulo: FAUUSP. Anais... São Paulo, 2017.

PAN, H.; BAHJA, F.; COBANOGLU, C. Analysis of U.S. theme park selection and international implications. Journal of Transnational Management, v. 23, n. 1, p. 22-38, 2018. doi: https://doi.org/10.1080/15475778.2018.1426943.

PEREIRA, A. Q.; CUNHA, G. B. Empreendimentos turístico-imobiliários e a modernização dos litorais metropolizados - Fortaleza-Ceará. Sociedade \& Território, v. 30, n. 2, p. 169-193, 2019. doi: https://doi.org/10.21680/2177-8396.2018v30n2ID14407.

PEREIRA, A. Q.; GOMES, I. R. Lazer, imobiliário e infraestrutura urbana do litoral cearense no século XXI. Caminhos de Geografia, Uberlândia: UFU, v. 19, n. 67, p. 109-225, 2018. doi: http://dx.doi.org/10.14393/RCG196708.

RALUCA, D. C.; GINA, S. Theme park: the main concept of tourism industry development. Annals of the University of Oradea, v. 17, n. 2, p. 641-646, 2008.

RODRIGUES, F. N. Turismo e meio ambiente: da inserção dos resorts à (in)sustentável gestão ambiental no Porto das Dunas, Aquiraz-CE. Dissertação (Mestrado em Geografia) Universidade Federal do Ceará, Fortaleza, 2016.

RYAN, C.; SHUO, Y. S. S.; HUAN, T.-C. Theme parks and a structural equation model of determinants of visitor satisfaction - Janfusan Fancyworld, Taiwan. Journal 
of Vacation Marketing, v. 16, n. 3, p. 185-199, 2010. doi: http://dx.doi. org/10.1177/1356766710372245.

SANTOS, M. F. Os impactos sócio-econômicos do parque Beto Carrero World na economia de Penha. Monografia (Graduação em Ciências Econômicas) - Universidade Federal de Santa Catarina, Florianópolis, 1997.

SIMS, S.; MESEV, V. Measuring urban sprawl and compactness: case study Orlando, USA. In: INTERNATIONAL CARTOGRAPHIC CONFERENCE, 25., June 2011, Paris. Proceedings... Paris, 2011.

TEA; AECOM. Theme index and museum index: the global attractions attendance report. [S.I.]: TEA, 2018.

TEA; AECOM. Theme index and museum index: the global attractions attendance report. [S.I.]: TEA, 2017.

TOLEDO, M. Com águas termais, Olímpia (SP) deve receber 500 mil pessoas em janeiro. Folha de S.Paulo, 2 jan. 2020. Disponível em: https://wwwl.folha.uol.com.br/ noticias/2016/folha-verao/. Acesso em: 15 maio 2020.

URRY, J. O olhar do turista. 3. ed. São Paulo: Studio Nobel, 2001.

ZUKIN, S. Learning from Disney World. In: ZUKIN, S. The cultures of cities. Cambridge, GB: Blackwell, 1995. p. 48-77.

Contribuição dos autores:

Alexandre Queiroz Pereira: sistematizou os dados secundários e interpretou as relações nas escalas internacional e nacional; rastreou e interpretou o estado da arte (parques e urbanização); organizou e produziu a cartografia e demais ilustrações; construiu o método de exposição, a disposição dos argumentos e a interpretação de todos os dados; fez o trabalho de campo e avaliou o texto pósrevisão, sugerindo trechos na conclusão.

Eustogio Wanderley Correia Dantas: sistematizou os dados e as fontes secundárias para analisar os fatos na escala urbana; interpretou o estado da arte nos temas referentes a metropolização e urbanização do espaço litorâneo; organizou e produziu a cartografia nas escalas metropolitana e regional; construiu o método de exposição, a disposição dos argumentos e a interpretação de todos os dados; avaliou o texto pós-revisão, sugerindo inserção de novas referências internacionais.

Recebido em: 25 fev. 2021 Aprovado em: 17 maio 2021 